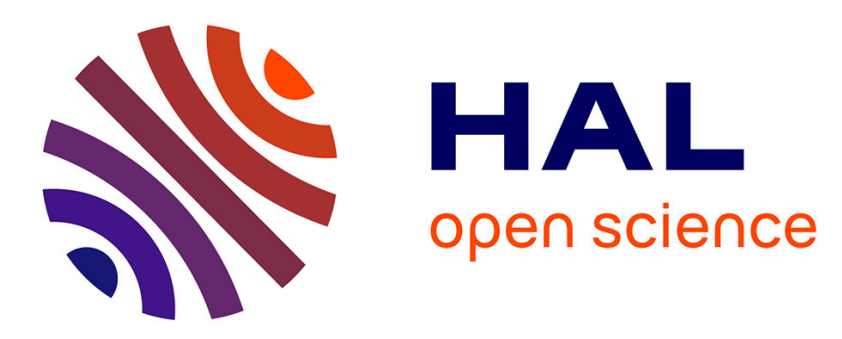

\title{
The Effect of an Electromagnetic Peening Process on Mumetal Properties
}

\author{
Aurélien Chazottes-Leconte, Emmanuel Sonde, Loup Plantevin, Charles \\ Joubert, Thibaut Chaise, Laurent Morel, Daniel Nelias, Hubert Razik
}

\section{- To cite this version:}

Aurélien Chazottes-Leconte, Emmanuel Sonde, Loup Plantevin, Charles Joubert, Thibaut Chaise, et al.. The Effect of an Electromagnetic Peening Process on Mumetal Properties. 2018 IEEE ICIT, Feb 2018, Lyon, France. 10.1109/ICIT.2018.8352290 hal-01800374

\section{HAL Id: hal-01800374 \\ https://hal.science/hal-01800374}

Submitted on 25 May 2018

HAL is a multi-disciplinary open access archive for the deposit and dissemination of scientific research documents, whether they are published or not. The documents may come from teaching and research institutions in France or abroad, or from public or private research centers.
L'archive ouverte pluridisciplinaire HAL, est destinée au dépôt et à la diffusion de documents scientifiques de niveau recherche, publiés ou non, émanant des établissements d'enseignement et de recherche français ou étrangers, des laboratoires publics ou privés. 


\title{
The Effect of an Electromagnetic Peening Process on Mumetal Properties
}

\author{
Aurélien Chazottes-Leconte ${ }^{1,2}$, Emmanuel Sonde ${ }^{2}$, Loup Plantevin ${ }^{1}$, Charles Joubert ${ }^{1}$, Thibaut Chaise ${ }^{2}$, Laurent \\ Morel $^{1}$, Daniel Nelias ${ }^{2}$, Hubert Razik ${ }^{1}$.
}

\author{
${ }^{1}$ Univ Lyon \\ UCB Lyon 1 \\ CNRS UMR5005 \\ Laboratoire Ampère, \\ F-69622, France
}

\author{
${ }^{2}$ Univ Lyon \\ INSA-Lyon \\ CNRS UMR5259 \\ $\mathrm{LaMCoS}$ \\ F-69621, France
}

\begin{abstract}
Peening processes are widely used in the industries to enhance the performance of the most solicited parts of mechanical pieces. Actual processes, like shot peening and low plasticity burnishing, are quite limited to a small depth of treatment circa $1 \mathrm{~mm}$ at maximum. A new process is developed based on pulsed electromagnetic fields. This method allows a better depth of treatment up to $5 \mathrm{~mm}$ and it can be easily monitored. A prototype was developed using a pulse current generator and specifically designed inductor. This prototype was used on mumetal for the preliminary tests. Indeed, its maximal permeability and coercivity are highly impacted by the presence of stresses. Using specifics sensors, some changes occur after treatment on mumetal samples and can be observed.
\end{abstract}

Keywords-Electromagnetic Peening processes; Peening process; Pulse current generator; Needle sensor; H-Coi;Magnetic properties; Magntic materials; mumetal properties.

\section{INTRODUCTION}

Peening processes are widely used in industries to introduce compressive residual stresses in the most solicited parts of mechanical pieces. Properly applied, the process significantly increases the lifespan of these parts, especially under fatigue solicitations or corrosive environment, and will reduce or prevent the propagation of micro-cracks inside the material.

There are several different processes used to apply compressive residual stresses that can be thermal treatment, thermo-chemical, and mechanical. Nowadays, some of the main processes used in the industry are shot peening, ultrasonic shot peening, and low plasticity burnishing [1-2]. These processes are well known however they share one common disadvantage of a depth of treatment circa $1 \mathrm{~mm}$ at maximum [3].

Recently news processes breakthrough such as laser shock peening, cavitation peening and the new technology we described in the present paper. These technologies are very interesting for two aspects. First, there is no particles left on the piece which is not possible using the current classical process and second, it possible to reach several millimeters of treatment depth. With the electromagnetic peening technology, electromagnetic pulses are used to generate eddy currents inside metallic materials to introduce plastic stresses with Lorentz forces. If the electromagnetic pulse is high and fast enough, it will generate a plastic flow and therefore residual stress. According to the simulation of the process, which is not presented here, it is possible to expect around $5 \mathrm{~mm}$ or even more of treated depth [4]. The level of residual stress and the treatment depth can be controlled with the energy and the frequency of the electromagnetic pulse.

To generate electromagnetic pulses suitable to apply compressive residual stresses, a pulsed current generator with a custom inductor is used [5]. This inductor was specially developed for this application as the current pulse generator. It was designed to prove the feasibility of this technology. It can reach high currents peaks of $180 \mathrm{kA}$ nominal current with a pseudo frequency of $35 \mathrm{kHz}$.

To investigate the generation of residual stresses inside materials, a material with a low yield strength is chosen to begin with. It will require less energy to introduce compressive residual stress than an industrial material. With a highpermeability and a relative low yield strength when annealed, the mumetal is a good candidate for this experiment. Especially its maximal permeability and coercivity are affected by the presence of stresses. By recording the hysteresis cycle of mumetal's workpiece before and after an electromagnetic peening, a significant variation of the magnetic properties is expected to be observed.

\section{Pulse Current Generator}

\section{A. Generator Characteristics}

As it is a proof of concept for electromagnetic peening, this current generator must be versatile. Indeed, as we intended to work with a broad range of material samples we may have to change electrical parameters. The nominal characteristics of the pulse generator were defined as follows. 
TABLE I. MAIN CHARACTERISTICS FOR PULSE CURRENT GENERATOR

\begin{tabular}{|l|l|}
\hline Peak current & 50 to $180 \mathrm{kA}$ \\
\hline Pseudo-frequency & $30 \mathrm{kHz}$ Nominal \\
\hline Load inductance & $250 \mathrm{nH}$ Maximum \\
\hline Lifetime & $>1000$ pulses \\
\hline
\end{tabular}

\section{B. Circuit Schematic}

A RLC circuit was chosen for this application. It is described schematically in fig. 1 [6-7]. A high voltage power supply provides the necessary current to charge a bank of capacitors. This capacitor bank includes 24 high voltage polypropylene capacitors of $2.6 \mu \mathrm{F}$ in parallel to provide a maximum energy of $12.5 \mathrm{~kJ}$ for the system. Each capacitor can be easily removed or added from the bank to achieve a modularity in the overall impedance of the system. The main switch, SW1, which is a triggered spark gap, can discharge the energy stored at a specific voltage. With this flexibility on the rated voltage, it is possible to change the maximum current for each pulse.

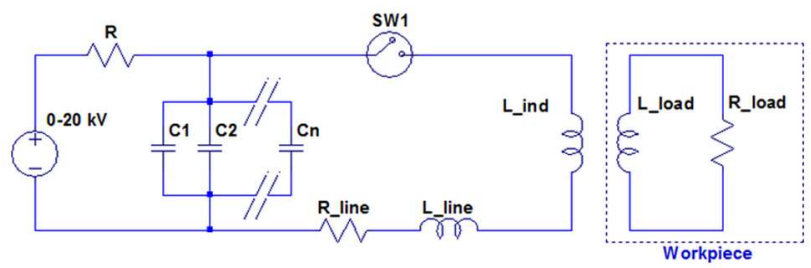

Fig. 1. Equivalent circuit of the pulse current generator based on a highvoltage capacitor bench with a closing switch SW1 (sparkgap) and the inductor. $\mathrm{R}-\mathrm{L}$ _line represents the parasitic elements of the line.

One side of the capacitor bank is grounded and the other side is linked to the high voltage power supply and the sparkgap. The capacitor bank is charged through a resistor $\mathrm{R}$ to limit the current and protect the power supply. Capacitors are placed in a circular shape around the central main power connection. The goal of this array is to balance impedances between all capacitors. In that way, all capacitors provide the same current.

The output of the sparkgap is directly connected to the branch with the inductor $\mathrm{L}$ ind and the parasitic elements ( $\mathrm{R}$ line and $\mathrm{L}$ line). This branch is exposed to high voltage only a short amount of time during pulses which limits the dielectric stress on the insulating coating of the inductor.

\section{Inductor Design}

A specific inductor was designed for this application based on the analytical model developed previously, it consist in a 3 turn coil with a spiral shape, an inner radius of $7 \mathrm{~mm}$ and outer radius of $13 \mathrm{~mm}$. Each coil has a cross section of 4 by $1 \mathrm{~mm}$ with $1 \mathrm{~mm}$ of space between each turn. Base on analytic formulas [8], the inductance of the inductor is $220 \mathrm{nH}$. The inductor is formed with $\mathrm{Cu}$-ETP copper alloy with a very low electrical resistivity $\left(1.724 \times 10^{-8} \Omega / \mathrm{m}\right)$. During a test, the inductor is supposed to be at $1 \mathrm{~mm}$ from the sample.

To insure a good electrical insulation of the inductor, an acrylic socket is used with a clear epoxy to drown in the inductor into. The usage of these compounds allows the possibility of a visual inspection of the inductor [9-10]. An aluminum shield of
$5 \mathrm{~mm}$ thick is used to contain the inductor and its insulating coating. Figure 2 shows a representation of the actual inductor with and without its protectives layers.

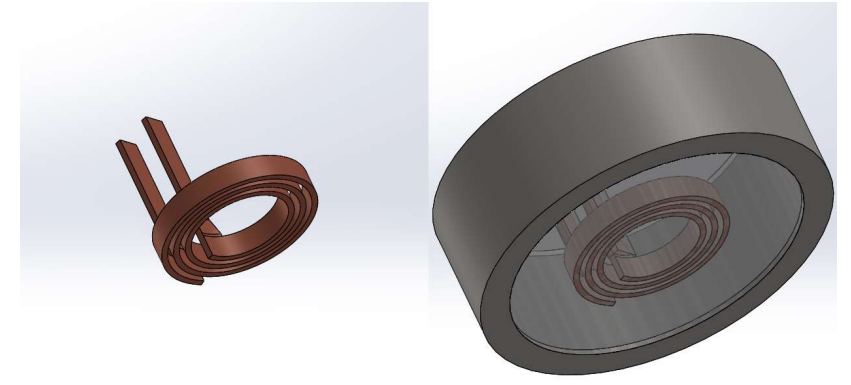

Fig. 2. Design of the inductor: (a) spiral coil made of Cu-ETP, (b) Coil with its protective socket of polycarbonate and epoxy and its steel shield.

\section{Experimental setup}

The electromagnetic peening prototype is described in the fig. 3. As shown, the capacitor bank is fully equipped with capacitors and the maximum capacitance is used. The inductor and the sparkgap are connected together with the bank using busbars. A Spellman SLM20P1200 high voltage power supply is used to charge the capacitor with a maximum current of 60 $\mathrm{mA}$. The inductor current is measured with a Powertek CWT $1500 \mathrm{~B} *$ coil. The voltage is supposed to be read out with the power supply and an extra North Star high voltage probe PVM1 is also used. To record all the data, a LeCroy WaveJet 314A oscilloscope, with $100 \mathrm{MHz}$ bandwidth and $1 \mathrm{GSa} / \mathrm{s}$ is used and is triggered by the igniting system of the sparkgap.

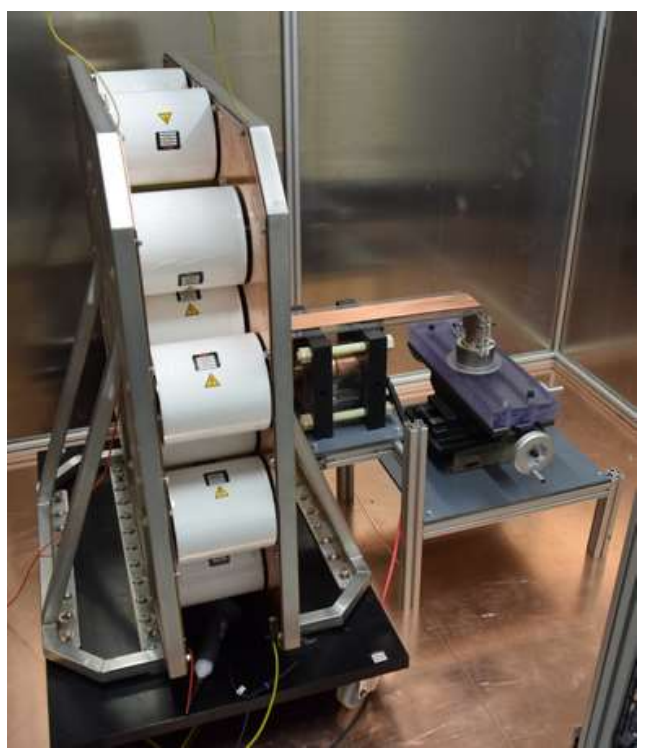

Fig. 3. View of the prototype of pulse current generator with the capacitor bank, the sparkgap and the inductor. A xy table is used to move the workpiece for multiple shots on different locations with a good precision.

The workpiece in mumetal is placed between the inductor and acrylic plate which is on an XY table. It allows the workpiece to be in a precise position or repetitive shots on different places within a tenth of millimeter of precision. For the preliminary experiments on the mumetal, a single shot is made. 
To hold down the inductor and the workpiece a press system is used to avoid recoil from the electromagnetic reaction.

This pulsed current generator is placed in a faraday chamber to prevent electromagnetic interferences. Another aspect of this chamber, is that it can prevent certain mechanical failures of the inductor or the sample under the stress.

\section{CHARACTERIZATION TOOLS}

The electromagnetic properties like the permeability and the coercive field of ferromagnetic materials are highly sensitives to micro-structural variations, especially with high permeability materials like mumetal. When applying a peening process to a workpiece, it changes the micro-structural state for the first millimeters depth. So, a change of these parameters can be observed. To quantify these variations, the local flux density B inside the material and surface $\mathrm{H}$ field can be monitored when the material is properly excited.

\section{A. Needles Sensors}

For measuring the local induction $\mathrm{B}$ in a workpiece, the needle-probe technique is the only one nondestructive method available. The principle is described in fig. 4. This method is very interesting from a mechanical point of view because it does not change the mechanical stress state of the material during measures [11-12].

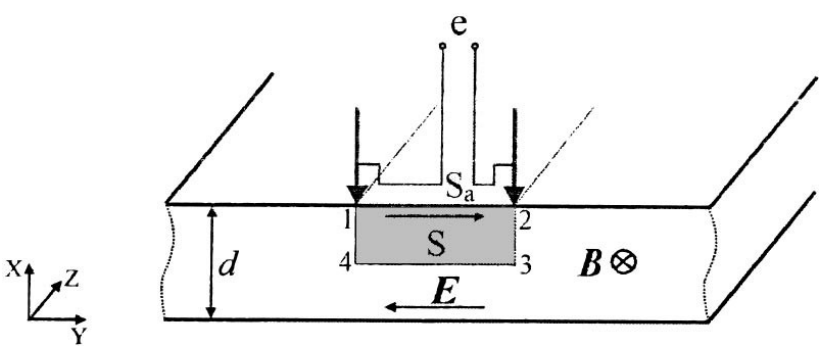

Fig. 4. Principle of the needle sensor for B measurement. The two needles are spaced by a length $\mathrm{L}$.

Based on the Maxwell's second equation, it allows for the evaluation of the local magnetic flux in the material with the voltage drop measured between the two needles. It is possible to consider only a half thickness of the material if the induction $\mathrm{B}=\mathrm{B}_{\mathrm{z}}(\mathrm{x}, \mathrm{t}) \cdot \mathrm{l}_{\mathrm{z}}$ has only a space dependency along $\mathrm{x}$ and if the needles are relatively far away from the edge. Under these conditions, the induced voltage $\mathrm{e}(\mathrm{t})$ is given by the flux variation inside the section $\mathrm{S}+\mathrm{S}_{\mathrm{a}}$. In our case, we minimized the section of air $\mathrm{S}_{\mathrm{a}}$, to only consider the section $\mathrm{S}$ of the material.

$$
\mathrm{e}(\mathrm{t}) \approx \frac{1}{2} \cdot \mathrm{d} \cdot \mathrm{L} \cdot \frac{\mathrm{dB}}{\mathrm{dt}}
$$

The previous relation (1) gives resulting voltage with the geometric parameter defined in the fig. 4 . This signal must be amplified with a proper system because the measured voltage is less than $100 \mu \mathrm{V}$.

\section{B. H-Coil Sensor}

An H-coil or an induction coil is used to track the magnetic flux $\varphi$ on the surface of the treated workpiece. The voltage given by this sensor results from the Faraday's law of induction [12].

$$
\mathrm{V}=-\mathrm{n} \cdot \frac{\mathrm{d} \varphi}{\mathrm{dt}}=-\mu_{0} \cdot \mathrm{n} \cdot \mathrm{A} \cdot \frac{\mathrm{dH}}{\mathrm{dt}}
$$

Where $\mathrm{n}$ is the number of turns in the coil and A the effective area corresponding to the inner surface of the coil.

\section{Sensors Prototype}

A specific probe prototype was created to monitor B-H field. Figure 5 presents the existing sensors with its $3 \mathrm{~d}$ printed support.

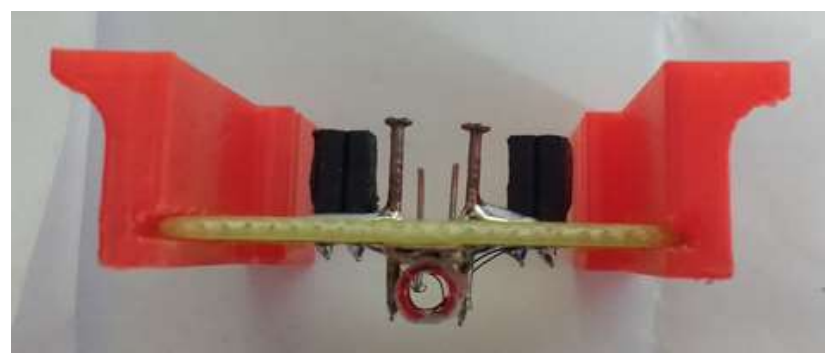

Fig. 5. B-H sensors with its support. The needle sensor is made with two brass needles. H-coil consist in two layers of 100 turns each.

The two brass needles are spaced by $1 \mathrm{~mm}$ and the H-coil is placed in between. The acquisition board connected to the sensors needs to be calibrated before each measurement. It means that coil parameters and needles don't have to be known to use it as long as it is properly calibrated. With this sensor it is possible to do a local measure of the $\mathrm{B}(\mathrm{t})$ and $\mathrm{H}(\mathrm{t})$ field simultaneously. So the static and dynamic shapes of the hysteresis curves can be plotted.

\section{RESULTS}

As it mentioned earlier, we applied some residual stresses on mumetal. We used annealed mumetal with a low yield strength around $160 \mathrm{Mpa}$ and high maximal permeability of around $7 \times 10^{4}$. For these experiments, we used workpieces of $125 \mathrm{~mm}$ in length, $30 \mathrm{~mm}$ large and $0.5 \mathrm{~mm}$ thick. We chose a longer workpiece than the diameter of the inductor for observing the parameters variation.

\section{A. Current Discharge}

For first experiments, the pulse current generator is not used at full power and a single shot has been done in the middle of the workpiece. According to simulations, an electromagnetic pulsed of $3.1 \mathrm{~kJ}$ should be enough to observe some changes in mumetal properties. 


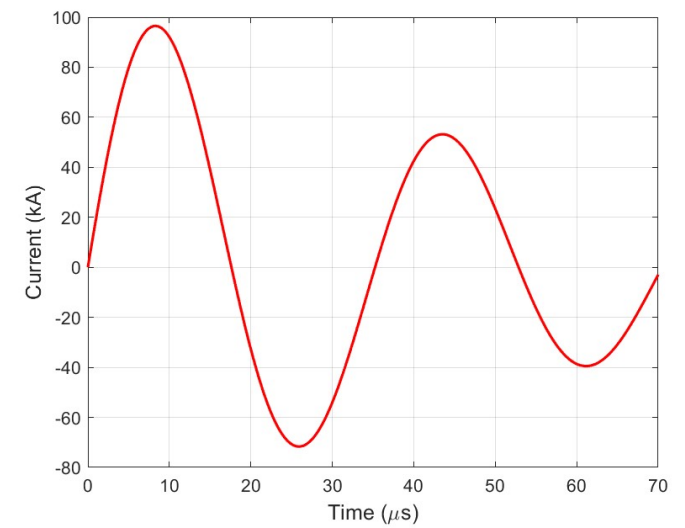

Fig. 6. Inductor current measured during a test on mumetal at $10 \mathrm{kV}$ with a Rogowski coil.

The measured experimental current through the inductor is shown in fig. 6. During this discharge, a peak current of $90 \mathrm{kA}$ with a pseudo frequency slightly lower than $30 \mathrm{kHz}$ was recorded.

\section{B. Sample Shape Measurement}

For a sufficiently thin workpiece with enough residual stresses in it, the accommodation of strains in the material may induce a macroscopic deflection. Thus, for a thin workpiece, containing compressive residual stresses at its surface, a concave shape is expected in the treated area [3].

A stereo-digital image correlation is used to evaluate the deformation at the surface of the workpiece generated by oneshot at the middle of the workpiece. This measurement method is simple to implement compare to others methods and the precision of the system is circa one micrometer [13]. Only the treated area was measured and is represented as follow.

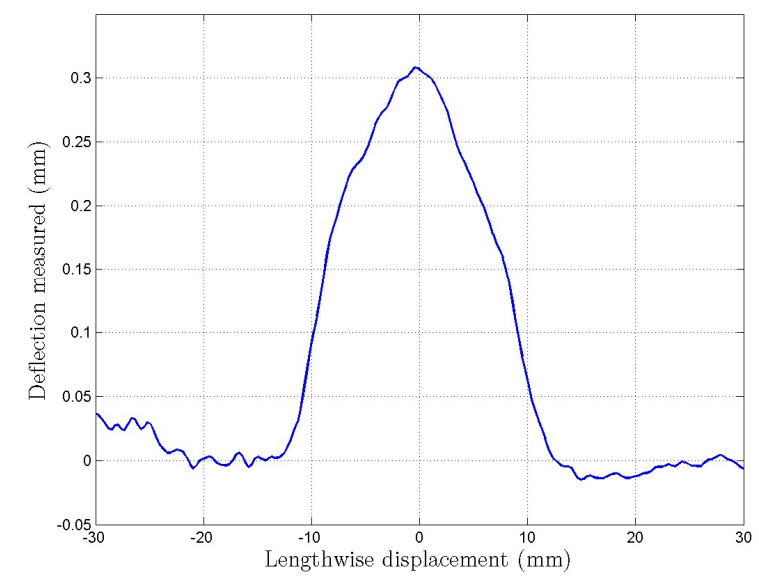

Fig. 7. Results of stereo-digital image correlation along the $x$ axis. the reference is taken in the middle of the workpiece.

The middle line along the length ( $\mathrm{x}$-axis) of the workpiece is taken as the reference line for the measurement. The results from the stereo-digital image correlation shows that a positive deflection does appear after treatment underneath the inductor area. The top height of the deflection is around $0.3 \mathrm{~mm}$. This deflection can be directly related to the presence of residual stresses. Since this phenomenon is directly linked to the amount of stresses, it is possible to evaluate them by measuring the height of the deflection. However, this result is not accurate and it is more quantitative than quantitative.

\section{Coercivity and Permeability Measurement}

After treatment, the B-H sensors are used on the workpiece to record the local hysteresis cycle. These measurements are done along the same reference line established for stereo-digital image correlation. The interest is to relate the visible deformation due to residual stresses with the magnetic parameters.

A u-shape magnetization core is used to apply a variable magnetic field to the mumetal workpiece at a frequency of 10 $\mathrm{Hz}$. Based on the local hysteresis cycles recorded, it is possible to extract the local coercivity and maximal permeability of the mumetal using a matlab routine and the sensors data.
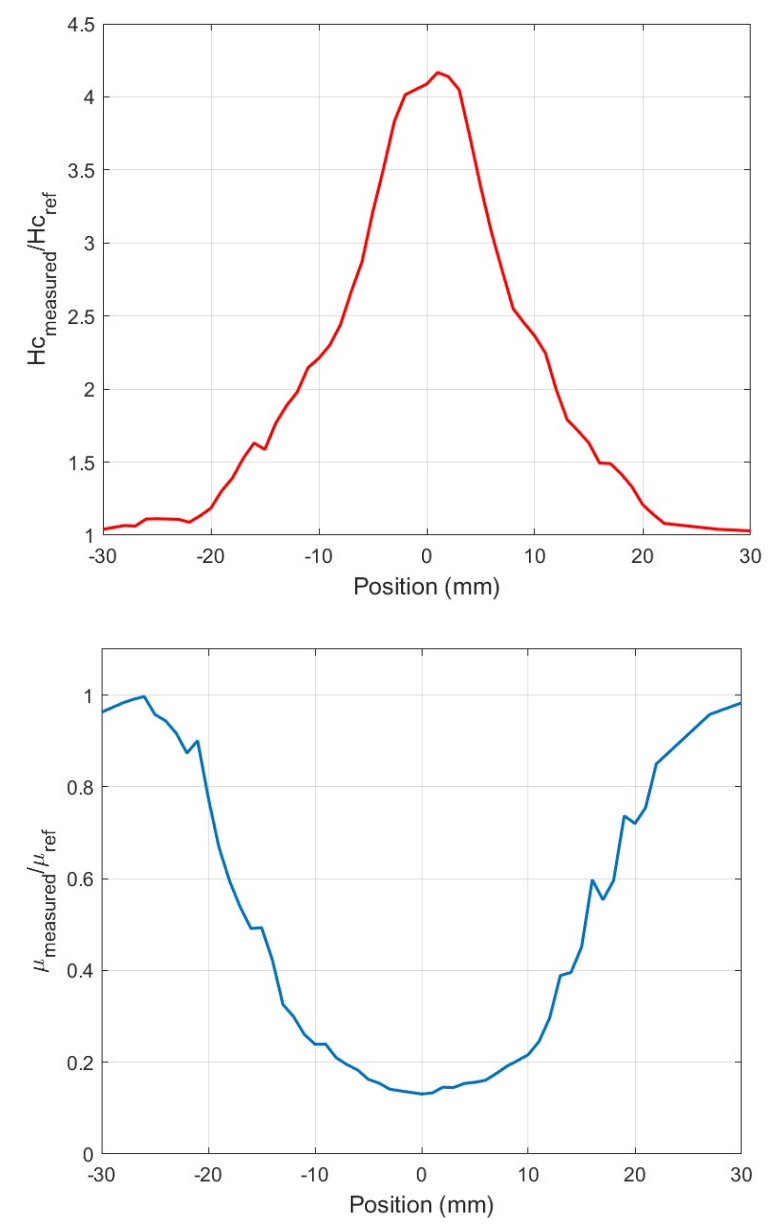

Fig. 8. Relative coercivity and the maximal permeability of the mumetal along the reference line.

As we can see with these results, the maximal permeability and the coercivity are strongly impacted by the electromagnetic peening shot. The peening process induces a lot of dislocations 
inside the workpiece, residual stresses and maybe change the grain size. As it is shown in the literature [14], the coercivity and maximal permeability are affected by these parameters.

The affected area seems to be larger than the corresponding deformed area (cf. Fig. 7). The observed deflection is related to sufficient amount compressive residual stresses in the inner area of the inductor (between $-12 \mathrm{~mm}$ and $12 \mathrm{~mm}$ ). However, some residual stresses are present in the outer area but the accommodation of the strains might be not enough to induce a deformation. Some dislocations are present too and may affect the grain size. So, these effects and the stresses have an effect on the magnetic parameters as shown in fig. 8 .

\section{CONCLUSION}

The results on the mumetal shows that the electromagnetic peening process has an influence on mumetal properties. Some investigations have to be done to evaluate the amount of residual stresses. By decorrelating the different measures, it maybe possible to determine the local residual stress. On another side with this sensor it might be possible to create a two-dimensional cartography of the stresses in a ferromagnetic workpiece and to check the uniformity of the process.

\section{ACKNOWLEGMENT}

This work is supported by the Carnot Institute of Lyon ("ElectroMagnetic Peening" (EMP) Project).

\section{REFERENCES}

[1] Chaise T., Nélias D. "Contact pressure and residual strain in 3D elastoTplastic rolling contact for a circular or elliptical point contact." Journal of Tribology 133, 2011, pp 041402T1T9.

[2] Chaise T., Nélias D., Sadeghi F. "On the effect of isotropic hardening on the coefficient of restitution for single or repeated impacts using a semi analytical method." Tribology Transactions 54, 2011, pp 714T722.
[3] Barralis Jean ,Castex Louis and Maeder Gérard. "Precontraintes et traitements superficiels". Techniques de l'ingénieur Traitements thermiques superficiels et thermochimiques, 1999.

[4] Emmanuel Sonde, Thibaut Chaise, Daniel Nelias, Vincent Robin. Numerical simulation of electromagnetic surface treatment

[5] Lehr, Jane, and Pralhad Ron. Foundations of Pulsed Power Technology. Hoboken, NJ, USA: John Wiley \& Sons, Inc., 2017.

[6] Werner Hartmann, Michael Rumheld. "Design of a High Current Pulse Generator for Magnetoforming," 310-13. IEEE, 2004.

[7] Nashilevskiy, A. V., G. G. Kanaev, V. I. Krauz, V.V. Myalton, G. E. Remnev, and V. P. Vinogradov. "High-Current Pulse Generator for Plasma Focus," 923-26. IEEE, 2011.

[8] E. B Rosa, F.W. Grover. Inductance Calculations. Scientific Papers of the Bureau of Standards no 169 (1916) 163-171

[9] VanBenthysen, Reid, Ethan Thibaudeau, and Brad L. Kinsey. "Effect of Specimen Planar Area on Electromagnetic Flanging." Journal of Manufacturing Processes 15, no. 2 (April 2013): 194-200.

[10] Thibaudeau, Ethan, and Brad L. Kinsey. "Analytical Design and Experimental Validation of Uniform Pressure Actuator for Electromagnetic Forming and Welding." Journal of Materials Processing Technology 215 (January 2015): 251-63.

[11] De Wulf, Marc, Luc Dupré, Dimitre Makaveev, and Jan Melkebeek. "Needle-Probe Techniques for Local Magnetic Flux Measurements." Journal of Applied Physics 93, no. 10 (May 15, 2003): 8271-73.

[12] S. Tumanski. Handbook of Magnetic Measurements. CRC, (2011) $164-$ 186.

[13] Stéphane Roux, Julien Réthoré, François Hild. Digital Image Correlation and Fracture: An Advanced Technique for Estimating Stress Intensity Factors of 2D and 3D Cracks. Journal of Physics D: Applied Physics, IOP Publishing, 2009, 42, 214004 (21pp).

[14] I. Preece, R. Thomas. The 77 Effects of Various Stresses on Mumetal: Percent Ni-14 Percent Fe-5 Percent Cu-4 Percent Mo. IEEE Transactions on Magnetics (Vol: 7, Issue: 3, September 1971): 554-557. 